\title{
Better Walking Performance in Older Children With Cerebral Palsy
}

\author{
Elisabet Rodby-Bousquet RPT, Gunnar Hägglund MD, PhD
}

Published online: 29 March 2011

(c) The Author(s) 2011. This article is published with open access at Springerlink.com

\begin{abstract}
Background Children with cerebral palsy $(\mathrm{CP})$ often walk with a slower speed and a higher energy cost. Their walking performance and choice of mobility method may vary in different environments. Independent mobility is important for activity and participation.

Questions/purposes We described walking performance at different distances and environments in relation to gross motor function, CP subtype, and age.

Patients and Methods We performed a cross-sectional study including all 562 children 3 to 18 years with CP living in southern Sweden during 2008. Data were extracted from a Swedish CP register and healthcare program. The Functional Mobility Scale (FMS) was used for rating mobility at home $(5 \mathrm{~m})$, at school $(50 \mathrm{~m})$, and in the
\end{abstract}

One of the authors (ER-B) was supported by the Promobilia Foundation, the National Association for Disabled Children and Youth (RBU), and the Centre for Clinical Research, Västerås. The other author $(\mathrm{GH})$ was supported by the Medical Faculty,

Lund University Hospital.

Each author certifies that his or her institution has obtained Ethical approval from the Medical Research Ethics Committee at Lund University (LU-443-99) and that all investigations were conducted in conformity with ethical principles of research.

This work was performed at the Department of Orthopaedics, Lund University, University Hospital, Lund, Sweden, and at the Centre for Clinical Research, Uppsala University, Central Hospital, Västerås, Sweden.

E. Rodby-Bousquet, G. Hägglund ( $₫)$

Department of Orthopaedics, Lund University,

University Hospital, 22185 Lund, Sweden

e-mail: Gunnar.Hagglund@med.lu.se

E. Rodby-Bousquet

Centre for Clinical Research, Uppsala University,

Central Hospital, 72189 Västerås, Sweden

e-mail: elisabet.rodby_bousquet@med.lu.se community $(500 \mathrm{~m})$. The FMS scores were analyzed in relation to Gross Motor Function Classification System (GMFCS) level, CP subtype, and age.

Results In this population, $57 \%$ to $63 \%$ walked 5 to $500 \mathrm{~m}$ without walking aids and $4 \%$ to $8 \%$ used walking aids. We found a correlation between FMS and GMFCS. The walking performance varied between the subtypes from $96 \%$ to $98 \%$ in those with spastic unilateral CP to $16 \%$ to $24 \%$ in children with dyskinetic CP. An increased proportion of children walked independently on all surfaces in each successive age group.

Conclusions The overall walking performance increased up to 7 years of age, but the proportion of children walking independently on uneven surfaces was incrementally higher in each age group up to 18 years. The ability to walk on uneven surfaces is important for achieving independent walking in the community.

\section{Introduction}

Cerebral palsy (CP) is the most common cause of motor disability in childhood $[1,10,30,36]$. The diagnosis includes children with a wide range of mobility from independent walking to assisted (dependent) wheeled mobility.

Normal walking is extremely efficient and advances the body safely from place to place with a minimum of energy [8]. Children with $\mathrm{CP}$ often start to walk later than nondisabled children [20] and they walk with a slower speed and higher energy cost [7]. There is a strong correlation between the energy cost of walking and the degree of motor impairment [19, 31]. There is also increased energy consumption when walking with assistive devices $[6,21,32,38]$. Many children with CP walk in a crouched 
posture [8, 15, 40, 41]. The crouched gait often worsens over time as a result of increasing muscle contractures, increasing body weight, and decreasing muscle strength [22]. Thus, the achieved walking ability is not always maintained through adolescence and adulthood [4, 18, 35].

Independent mobility is important for activity, participation, and self-sufficiency, reducing the dependence on caregivers and the environment [5, 26, 28, 29, 37]. Safety and efficiency are important factors when choosing mobility methods for different environments [28]. Environmental and personal factors influence the performance, what a child actually does do in a daily life situation [16, 42]. Older children and adolescents with CP are more active outside the home with friends than younger children [26] and the ability to walk on uneven surfaces is important to achieve independent mobility and improve accessibility in the community, where different surfaces, inclines, curbs, and stairs are more common [28]. Knowledge of the walking performance in a total population of children with $\mathrm{CP}$ is of importance for healthcare planning as well as for prediction of future performance in a young child with $\mathrm{CP}$. We presume the walking performance in children with $\mathrm{CP}$ depends on the child's gross motor function, CP subtype, and age and varies at different distances and environments.

Our purposes were (1) to describe the most frequent mobility method for different distances and environments in a total population of children with $\mathrm{CP}$; (2) to examine the association between walking performance and level of gross motor function, CP subtype; and (3) to describe the walking performance in different age groups.

\section{Patients and Methods}

We performed a cross-sectional study in a total population of children with CP living in southern Sweden during 2008, in total 562 children aged 3 to 18 years (mean age, 10.9 years). There is a healthcare program for children with CP in Sweden (CPUP) [11, 12]. The associated register includes all children with CP born after January 1, 1990, living in the counties of Skåne and Blekinge, which have a total population of approximately 1.3 million. The number of children with $\mathrm{CP}$ in the area corresponds to a prevalence of 2.4 per 1000 live births [23, 39]. A search is made regularly to find all children with $\mathrm{CP}$ in the area and invite them to participate in CPUP, and almost all families (98\%) have agreed to participate [39]. Data from the CPUP register were used to analyze the most frequent mobility method in different environments in a total population of children with CP. The study was approved by the Medical Research Ethics Committee at Lund University.

The CPUP healthcare program includes a continuing standardized followup of motor function, clinical findings,
Table 1. The Functional Mobility Scale (FMS) Version 2

Questions

1. How does your child move around for short distances in the house? $(5 \mathrm{~m})$

2. How does your child move in and between classes at school? $(50 \mathrm{~m})$

3. How does your child move around for long distances such as at the shopping center? $(500 \mathrm{~m})$

Ratings

6. Independent on all surfaces

5. Independent on level surfaces

4. Uses sticks (one or two)

3. Uses crutches

2. Uses a walker or frame

1. Uses wheelchair

C. Crawling

N. Does not apply, eg, child does not complete the distance

and treatment. The child is examined annually by its local physiotherapist. The recording form (at http://www.cpup.se) includes the Functional Mobility Scale (FMS) [9] Version 2 with information on the child's walking performance at three specific distances: $5 \mathrm{~m}, 50 \mathrm{~m}$, and $500 \mathrm{~m}$ representing the child's mobility at home, at school, and in the community, respectively (Table 1). The mobility is rated according to the need of assistive devices and is assessed by questions put to the child or parent and not by direct observation. The FMS is reliable, valid, and sensitive [9] with substantial agreement between direct observation and parental report [14].

The FMS ratings were analyzed in relation to level of gross motor function, CP subtype, and age. To analyze data, the children were divided into different age groups according to the Swedish school system: 3 to 6,7 to 9,10 to 12,13 to 15 , and 16 to 18 years (Table 2). The gross motor function for each child was determined by the child's physiotherapist using the Gross Motor Function Classification System (GMFCS) [24, 27], a five-level system for children and youth with $\mathrm{CP}$ based on selfinitiated movement, in which Level I describes the highest level of function and Level $\mathrm{V}$ the lowest. The CP subtypes were classified by the child's neuropediatrician according to Surveillance of Cerebral Palsy in Europe (SCPE) [36] as spastic unilateral, spastic bilateral, dyskinetic, ataxic, and unclassified or mixed CP. The classification is primarily based on neurologic signs as spastic, dyskinetic, and ataxic. The spastic subtype is divided into unilateral (hemiplegia) or bilateral (diplegia, tetraplegia) depending on localization.

Kruskal-Wallis test showed no differences in distribution of GMFCS levels $(\mathrm{p}=0.783)$ or classified CP subtypes $(\mathrm{p}=0.263)$ between the age groups (Table 2$)$. 
Table 2. Details of the 562 children

\begin{tabular}{|c|c|c|c|c|c|c|c|c|c|c|c|c|c|}
\hline \multirow[t]{2}{*}{ Age (years) } & \multirow[t]{2}{*}{ Number of children } & \multicolumn{2}{|c|}{ Gender } & \multicolumn{5}{|c|}{ GMFCS level } & \multicolumn{5}{|c|}{ CP subtype } \\
\hline & & Boys & Girls & I & II & III & IV & $\mathrm{V}$ & SU & SB & DY & AT & UC \\
\hline $3-6$ & $116(20.6 \%)$ & 67 & 49 & 51 & 9 & 21 & 16 & 19 & 25 & 27 & 21 & 7 & 36 \\
\hline $7-9$ & $104(18.5 \%)$ & 53 & 51 & 52 & 14 & 8 & 19 & 11 & 35 & 38 & 13 & 9 & 9 \\
\hline $10-12$ & $117(20.8 \%)$ & 67 & 50 & 51 & 22 & 14 & 17 & 13 & 38 & 47 & 17 & 5 & 10 \\
\hline $13-15$ & $117(20.8 \%)$ & 78 & 39 & 59 & 14 & 7 & 18 & 19 & 37 & 49 & 16 & 13 & 2 \\
\hline 16-18 & $108(19.2 \%)$ & 61 & 47 & 51 & 17 & 14 & 14 & 12 & 28 & 48 & 16 & 14 & 2 \\
\hline Total & 562 & 326 & 236 & 264 & 76 & 64 & 84 & 74 & 163 & 209 & 83 & 48 & 59 \\
\hline
\end{tabular}

GMFCS = Gross Motor Function Classification System; CP = cerebral palsy; SU = spastic unilateral; SB = spastic bilateral; DY = dyskinetic; $\mathrm{AT}=$ ataxic; $\mathrm{UC}=$ unclassified or mixed type.

Table 3. Distribution of FMS scores at 5, 50, and $500 \mathrm{~m}$

\begin{tabular}{lccc}
\hline FMS & Home $5 \mathrm{~m}$ & School $50 \mathrm{~m}$ & Community $500 \mathrm{~m}$ \\
\hline 6 & $245(43.8 \%)$ & $238(42.5 \%)$ & $228(40.6 \%)$ \\
5 & $106(18.9 \%)$ & $97(17.3 \%)$ & $90(16.0 \%)$ \\
4 & $8(1.4 \%)$ & $8(1.4 \%)$ & $7(1.2 \%)$ \\
3 & $1(0.2 \%)$ & $0(0 \%)$ & $0(0 \%)$ \\
2 & $26(4.6 \%)$ & $39(7.0 \%)$ & $15(2.7 \%)$ \\
1 & $62(11.1 \%)$ & $71(12.7 \%)$ & $102(18.1 \%)$ \\
$\mathrm{C}$ & $39(7.0 \%)$ & & \\
$\mathrm{N}$ & $73(13.0 \%)$ & $107(19.1 \%)$ & $120(21.4 \%)$ \\
Missing & $2(0.4 \%)$ & $2(0.4 \%)$ & $0(0 \%)$ \\
\hline
\end{tabular}

FMS $=$ Functional Mobility Scale.

Some children are not classified until 4 years of age so when the unclassified subtype was included, KruskalWallis showed a difference in subtypes between the age groups $(p=0.004)$ in which more children in the age group 3-6 years were unclassified. FMS ratings were available for all 562 children for $500 \mathrm{~m}$ but missing in two children for 5 and $50 \mathrm{~m}$ (Table 3).

Spearman's rank correlation $\left(r_{s}\right)$ was used to calculate correlations between FMS distances and between FMS and GMFCS levels. A linear by linear association test was used for analyzing trends in FMS related to GMFCS level and to age. The Kruskal-Wallis test was used to analyze differences related to $\mathrm{CP}$ subtype, and post hoc analyses were performed using the Mann-Whitney test. Kruskal-Wallis test was also used to analyze differences in the distribution of GMFCS levels and CP subtypes between the age groups. The relationship between independent walking and age was estimated using binary logistic regression adjusted for CP subtype. The analysis results in an odds ratio, which may be described as a ratio between two odds that expresses the probability for an event to occur. The results are presented as odds ratios (ORs) with $95 \%$ confidence interval and $\mathrm{p}$ values. The FMS was used as the outcome. Age was used
Table 4. Correlations between GMFCS levels and FMS at 5, 50, and $500 \mathrm{~m}$

\begin{tabular}{lcccc}
\hline Scales & GMFCS & FMS 5 m & FMS 50 m & FMS 500 m \\
\hline GMFCS & 1.000 & -0.907 & -0.912 & -0.911 \\
FMS 5 m & -0.907 & 1.000 & 0.972 & 0.948 \\
FMS 50 m & -0.912 & 0.972 & 1.000 & 0.969 \\
FMS 500 m & -0.911 & 0.948 & 0.969 & 1.000
\end{tabular}

All correlations are statistically significant $(\mathrm{p}<0.001)$, Spearman's correlations; GMFCS = Gross Motor Function Classification System; FMS $=$ Functional Mobility Scale.

as a categorical variable with 3 to 6 years as the reference category. Independent walking on all surfaces (FMS 6) and independent walking both on all surfaces and on level surfaces (FMS 6-5) were compared with all other categories. Odds is the ratio of the probabilities of walking without aids (FMS 6-5) compared with not walking without aids (FMS 4-1,C,N) and walking independently on all surfaces (FMS 6) compared with not walking on all surfaces (FMS 5-1,C,N) in different age groups. If the odds for walking are identical in each group, the odds ratio is equal to one. SPSS Version 17.0 (SPSS Inc, Chicago, IL) was used for all statistical analyses.

\section{Results}

According to the FMS, 63\% of the children walked without aids (FMS 6 or 5) at home, $60 \%$ at school, and $57 \%$ in the community setting (Table 3). Walking aids (FMS 4-2) were used by $4 \%$ to $8 \%$ at the three distances and a wheelchair (FMS 1) by $11 \%$ to $18 \%$. Crawling at home (FMS C) was reported for $7 \%$ of the children. For the remaining children, the ratings were $\mathrm{N}$ : does not apply (the child does not complete the distance) (Table 3). There were high correlations between the individual FMS scores at the three distances (Table 4). 
There was a high correlation between FMS and GMFCS for all FMS distances (Table 4). The FMS ratings were lower $(\mathrm{p}<0.001)$ with increasing distance for all GMFCS levels but most apparent for Level III followed by Levels II and IV (Fig. 1). Most children at GMFCS Levels I and II walked all distances independently but with more difficulties on uneven surfaces and longer distances for those at GMFCS II. Walking aids were most frequently used by children at Level III, 33\% at home and 52\% at school, whereas most of them used a wheelchair in the community. At GMFCS Level IV, $10 \%$ to $11 \%$ used walking aids for shorter distances, whereas most children used a wheelchair for all three distances. A majority of the children at Level $\mathrm{V}$ did not complete the distance (Fig. 1).
The FMS scores varied between the different subtypes $(p<0.001)$ and were lower with increasing distances, most pronounced in children with ataxia (Fig. 2). Post hoc analyses showed differences $(\mathrm{p}<0.001)$ between all subtypes at all three distances except among the spastic bilateral, ataxic, and unclassified subtypes. Almost all children with spastic unilateral $\mathrm{CP}$ walked all three distances without aids (FMS 6-5). Walking performance (FMS 6-2) was seen in $65 \%$ to $81 \%$ of children with ataxic CP, $52 \%$ to $64 \%$ with bilateral spastic CP, and $16 \%$ to $24 \%$ with the dyskinetic subtype. Unaided walking on uneven surfaces (FMS 6) was equally common in ataxic and spastic bilateral CP (30\%) and least common in dyskinetic CP (10\%). Walking aids were most used by children with
Fig. 1 Functional mobility at 5, 50, and $500 \mathrm{~m}$ related to Gross Motor Function Classification System (GMFCS) level. The Functional Mobility Scale (FMS) scores were lower $(\mathrm{p}<0.001)$ with increasing distance for all GMFCS levels.
Fig. 2 Functional mobility at 5, 50 , and $500 \mathrm{~m}$ related to cerebral palsy subtype. $\mathrm{SU}=$ spastic unilateral; $\mathrm{SB}=$ spastic bilateral; $\mathrm{AT}=$ ataxic; $\mathrm{DY}=$ dyskinetic; $\mathrm{UC}=$ unclassified or mixed type. The Functional Mobility Scale (FMS) scores varied between the different subtypes $(\mathrm{p}<0.001)$.
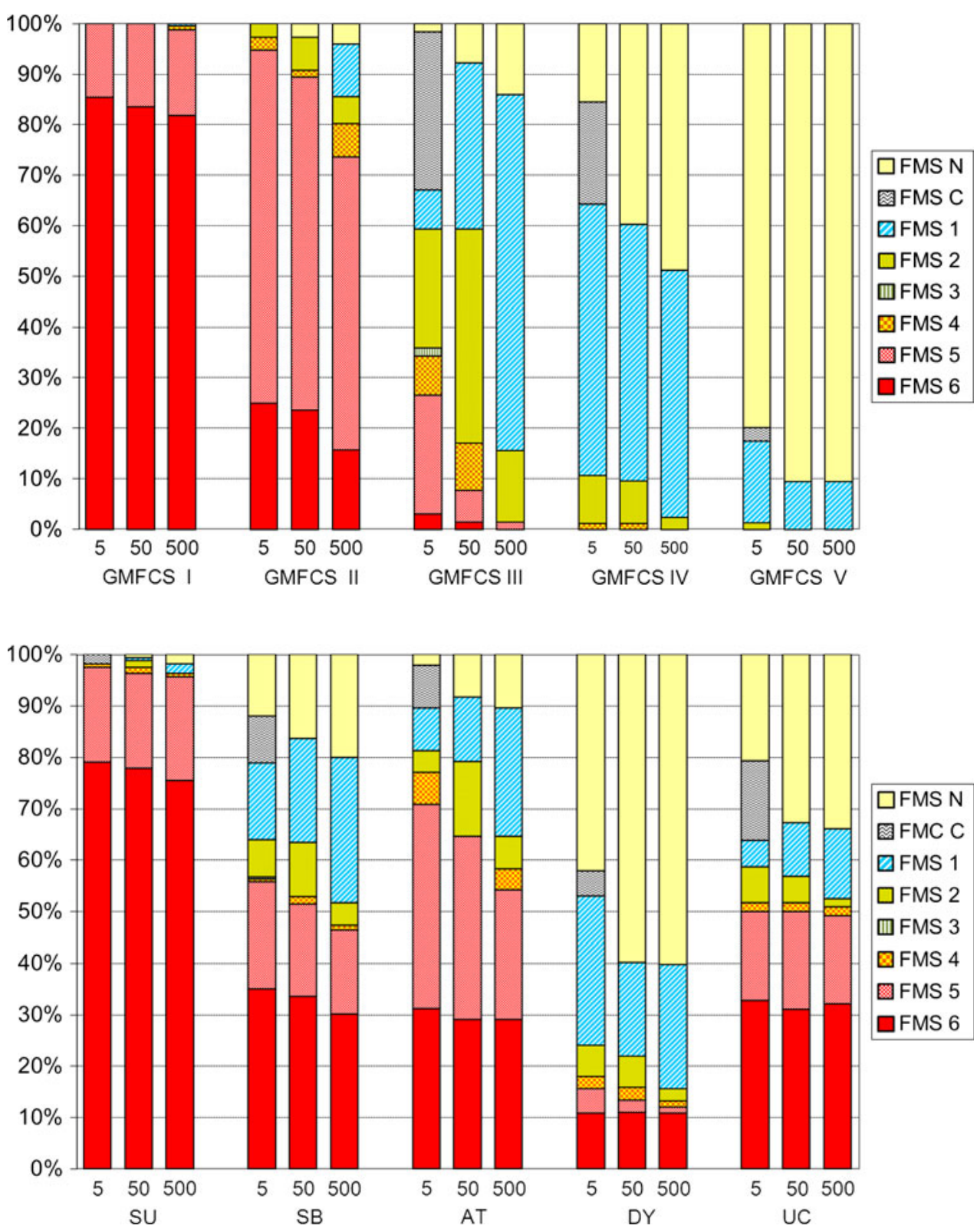
ataxic or spastic bilateral $\mathrm{CP}$ in the school environment (Fig. 2).

The overall functional mobility increased $(\mathrm{p}=0.011$, $\mathrm{p}=0.034, \mathrm{p}=0.016)$ with age at all three distances (Fig. 3). The walking performance without aids (FMS 6-5) increased from preschool children 3 to 6 years $(43 \%-51 \%)$ up to 7 year olds $(62 \%-65 \%)$ and then remained on that level up to 18 year olds. The ORs for walking without aids (FMS 6-5) was almost double in all age groups compared with 3 to 6 year olds but was almost the same in 7 and 18 year olds (Table 5). However, an increased proportion of children walked independently on all surfaces (FMS 6) in each successive age group up to 18 years. Compared with 3 to 6 year olds, the OR increased to 2.08 for 7 to
9 year olds and to 4.92 for 16 to 18 year olds at $500 \mathrm{~m}$ (Table 5). This implies that an 18 year old has a larger chance than a 7 year old of walking independently on all surfaces at home, at school, and in the community.

\section{Discussion}

The walking performance in children with $\mathrm{CP}$ varies as a result of personal and environmental factors. Knowledge of the walking performance in a total population is important for healthcare planning and for prediction of future performance in a young child with CP. The FMS describes walking performance at 5,50 , and $500 \mathrm{~m}$, representing the

Fig. 3 Functional mobility at 5 , 50 , and $500 \mathrm{~m}$ related to age. The Functional Mobility Scale (FMS) scores increased $(\mathrm{p}=$ $0.011, \quad \mathrm{p}=0.034, \quad \mathrm{p}=0.016)$ with age at all three distances.

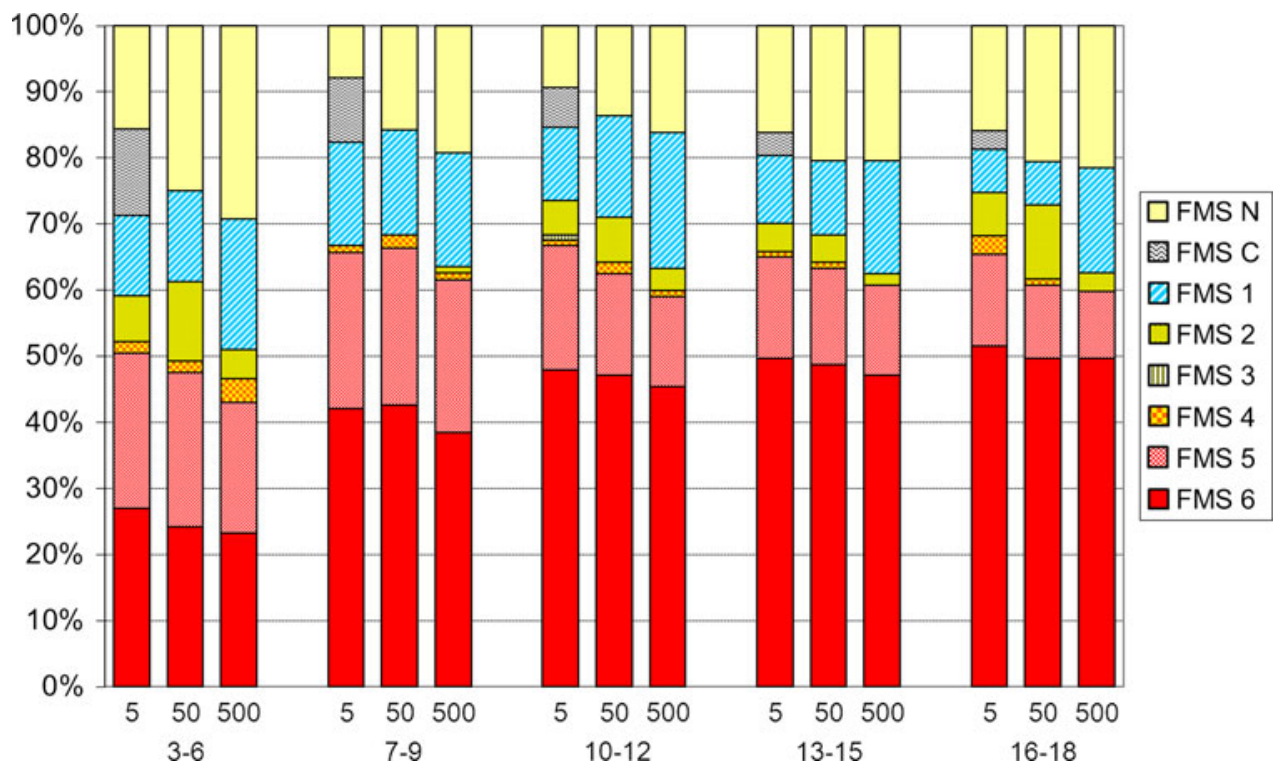

Table 5. Binary logistic regression of independent walking in relation to age adjusted for cerebral palsy subtypes

\begin{tabular}{|c|c|c|c|c|c|c|c|c|c|c|}
\hline Category & Age & OR $5 \mathrm{~m}$ & $(95 \% \mathrm{CI})$ & $\mathrm{p}$ Value & OR $50 \mathrm{~m}$ & $(95 \% \mathrm{CI})$ & $\mathrm{p}$ Value & OR $500 \mathrm{~m}$ & $(95 \% \mathrm{CI})$ & $\mathrm{p}$ Value \\
\hline \multirow[t]{5}{*}{ FMS 6} & $3-6$ & reference & & & & & & & & \\
\hline & $7-9$ & 1.84 & $(0.94-3.57)$ & 0.073 & 2.19 & $(1.12-4.29)$ & 0.023 & 2.08 & $(1.05-4.10)$ & 0.036 \\
\hline & $10-12$ & 2.56 & $(1.34-4.89)$ & 0.004 & 2.90 & $(1.51-5.59)$ & 0.001 & 3.18 & $(1.64-6.17)$ & $<0.001$ \\
\hline & $13-15$ & 3.00 & $(1.54-5.85)$ & 0.001 & 3.42 & (1.74-6.74) & $<0.001$ & 3.80 & $(1.91-7.53)$ & $<0.001$ \\
\hline & $16-18$ & 3.84 & $(1.94-7.60)$ & $<0.001$ & 4.17 & $(2.08-8.33)$ & $<0.001$ & 4.92 & (2.45-9.88) & $<0.001$ \\
\hline \multirow[t]{5}{*}{ FMS 5-6 } & $3-6$ & reference & & & & & & & & \\
\hline & $7-9$ & 1.53 & $(0.77-3.03)$ & 0.227 & 2.01 & $(1.01-3.99)$ & 0.047 & 2.17 & $(1.09-4.33)$ & 0.028 \\
\hline & $10-12$ & 1.82 & $(0.94-3.55)$ & 0.078 & 1.81 & $(0.93-3.51)$ & 0.081 & 2.05 & $(1.04-4.01)$ & 0.038 \\
\hline & $13-15$ & 1.53 & $(0.77-3.04)$ & 0.225 & 1.86 & $(0.94-3.68)$ & 0.077 & 2.34 & $(1.17-4.69)$ & 0.016 \\
\hline & $16-18$ & 1.83 & $(0.91-3.68)$ & 0.089 & 1.87 & $(0.94-3.74)$ & 0.076 & 2.55 & $(1.27-5.13)$ & 0.009 \\
\hline
\end{tabular}

Odds ratios (ORs) with 95\% confidence interval (CI) and p values for independent walking on all surfaces (FMS 6) and independent walking on level surfaces (FMS 5) compared with all other categories; age was used as a categorical variable with 3 to 6 years as the reference category; FMS = Functional Mobility Scale. If the odds for walking are identical in each group, the odds ratio is equal to one. The probability of walking without aids is almost double in all age groups compared with 3 to 6 year olds but is almost the same from 7 to 18 year olds. The OR for walking independently on all surfaces (FMS 6) is higher in each successive age group up to 18 years at all distances and environments. 
child's mobility at home, at school, and in the community, respectively. Our purposes were to describe the most frequent mobility method in a total population of children with $\mathrm{CP}$ and to examine the association between walking performance and GMFCS level, CP subtype, and age.

We note limitations to our study. First, the FMS ratings provide only the child's most frequently used mobility method. Some children may use several methods such as both walking with devices and using a wheelchair at school. Second, this is a cross-sectional study showing the difference between age groups at a specific moment, not changes over time.

In an analysis from the SCPE database comprising 10,042 children with $\mathrm{CP}$ in Europe, Beckung et al. [2] reported that in 5-year-old children, 54\% had unaided walking and $16 \%$ walked with aids. Rumeau-Rouquette et al. [34] in a French study reported that in 8- to 14-yearold children, $38 \%$ to $44 \%$ had unaided walking and $13 \%$ to $28 \%$ walked with aids. The number of children with unaided walking in the present study is similar to Beckung et al. but higher than Rumeau-Rouquette et al. In the previous studies, it is not clear at what distance or in which environment the walking ability was recorded. The proportion of children using walking aids was smaller in our study. The use of walking aids was most common in children at GMFCS Level III and in children with ataxic or spastic bilateral CP in the school environment. Several studies document increased energy consumption when walking with assistive devices [6, 21, 32, 38]. Jahnsen et al. [17] reported an increased experience of freedom, speed of locomotion, and reduced energy cost in adults with $\mathrm{CP}$ at GMFCS III when starting to use a wheelchair for mobility. Safety and efficiency are important factors when choosing mobility method for different environments [28]. This may explain why wheelchairs were more frequently used than walking aids and walkers were more frequently used than crutches and sticks. A rather high accessibility for wheeled mobility in the community and no charge for wheelchairs may increase the use of wheelchairs instead of walking aids in our study. The use of a wheelchair for those with limited walking ability may preserve energy and prevent physical fatigue and thereby maintain walking performance in adolescents and adults.

The walking performance increased with GMFCS level. A relationship between the FMS and the GMFCS would be expected but has, to our knowledge, not previously been examined. We found a high correlation between the two instruments, indicating that GMFCS is a good predictor of walking performance. FMS is constructed to measure functional mobility in children corresponding to GMFCS Levels I to IV. To discriminate assisted and independent wheelchair mobility, a further level, between FMS 1 and N, could be considered.
The number of children who walked independently increased up to 7 years of age. This is in agreement with the study by Bleck [3], who observed that walking ability reached a plateau by the age of 7 years. It is also in agreement with longitudinal analysis of motor growth curves showing peak motor performance at 6 to 7 years of age $[1,13,33]$. We found, however, that the proportion of children walking independently on uneven surfaces (FMS 6) was incrementally higher in each age group up to 18 years. Hanna et al. [13] reported increased gross motor function (ie, capability) in adolescents at GMFCS I-II. Palisano et al. [25] described improved walking performance outdoors in adolescents at GMFCS II. Ability to walk on uneven surfaces is important to achieve independent mobility and improve accessibility in the community, where different surfaces, inclines, curbs, and stairs are more common [28]. This has clinical relevance because older children and adolescents do more activities outside the home with friends than younger children [26]. Those at GMFCS I do more activities outside than those at Levels II-III [26]. This may be the result of their unrestricted walking performance. Hanna et al. [13] reported a decline in gross motor function in children at GMFCS III-V from 8 years of age. Strauss et al. [35] found a decline in walking ability from 20 years and Jahnsen et al. [17] observed a reduction in gross motor function in adults at GMFCS II-III, mostly as a result of lack of balance, fear of falling, pain, and exhaustion. Raja et al. [31] showed an increasing energy cost with each level of decreasing FMS score and doubled when walking outdoors on uneven surfaces compared with even surfaces indoors. This may explain why $59 \%$ of the children at GMFCS Level III walked $5 \mathrm{~m}$ at home, whereas only $16 \%$ walked $500 \mathrm{~m}$ in the community. In the present study we found no increased use of walking aids or wheelchair with age as reported for adults. In the CPUP program, the number of children who develop severe contractures or hip dislocation has been reduced [11, 12]. This improvement could result in a diminished or delayed decrease in walking performance. In general, younger children with CP get more intense treatment and followup by their physical therapists than adolescents and adults. A continuous treatment and training to increase oxygen uptake, improve balance and strength, maintain joint ROM, and reduce pain throughout adolescence may further improve walking performance or prevent a reduction in walking ability. The CPUP healthcare program continues to monitor the adolescents with $\mathrm{CP}$ as they grow into adults.

This study shows the most frequent mobility method at different distances and environments in an unselected total population of children with $\mathrm{CP}$. We found a variation in walking performance related to $\mathrm{CP}$ subtype and a high correlation between the FMS and the GMFCS. The overall 
walking performance increased up to 7 years of age, but the proportion of children walking independently on uneven surfaces was incrementally higher in each age group up to 18 years. The improved performance on uneven surfaces is important for achieving independent walking and improves accessibility in the community. Continuous followup and treatment to improve and maintain walking performance is important both in children and adolescents with $\mathrm{CP}$.

Acknowledgment We thank Andreas Rosenblad for statistical advice, $\mathrm{PhD}$ Biostatistician at the Centre for Clinical Research, Uppsala University, Central Hospital, Västerås.

Open Access This article is distributed under the terms of the Creative Commons Attribution Noncommercial License which permits any noncommercial use, distribution, and reproduction in any medium, provided the original author(s) and source are credited.

\section{References}

1. Beckung E, Carlsson G, Carlsdotter S, Uvebrant P. The natural history of gross motor development in children with cerebral palsy aged 1 to 15 years. Dev Med Child Neurol. 2007;49:751756.

2. Beckung E, Hagberg G, Uldall P, Cans C. Probability of walking in children with cerebral palsy in Europe. Pediatrics. 2008;121: e187-192.

3. Bleck EE. Locomotor prognosis in cerebral palsy. Dev Med Child Neurol. 1975;17:18-25.

4. Bottos M, Feliciangeli A, Sciuto L, Gericke C, Vianello A. Functional status of adults with cerebral palsy and implications for treatment of children. Dev Med Child Neurol. 2001;43:516-528.

5. Fernandes T. Independent mobility for children with disabilities. Int $J$ Ther Rehabil. 2006;13:329-333.

6. Franks CA, Palisano RJ, Darbee JC. The effect of walking with an assistive device and using a wheelchair on school performance in students with myelomeningocele. Phys Ther. 1991;71:570577; discussion 577-579.

7. Furukawa A, Nii E, Iwatsuki H, Nishiyama M, Uchida A. Factors of influence on the walking ability of children with spastic cerebral palsy. J Phys Ther Sci. 1998;10:1-5.

8. Gage JR, Deluca PA, Renshaw TS. Gait analysis: principles and applications. J Bone Joint Surg Am. 1995;77:1607-1623.

9. Graham HK, Harvey A, Rodda J, Nattrass GR, Pirpiris M. The Functional Mobility Scale (FMS). J Pediatr Orthop. 2004;24: 514-520.

10. Hagberg B, Hagberg G, Beckung E, Uvebrant P. Changing panorama of cerebral palsy in Sweden. VIII. Prevalence and origin in the birth year period 1991-94. Acta Paediatr. 2001;90: 271-277.

11. Hagglund G, Andersson S, Duppe H, Lauge-Pedersen H, Nordmark E, Westbom L. Prevention of dislocation of the hip in children with cerebral palsy. The first ten years of a population-based prevention programme. J Bone Joint Surg Br. 2005;87:95-101.

12. Hagglund G, Andersson S, Duppe H, Lauge-Pedersen H, Nordmark E, Westbom L. Prevention of severe contractures might replace multilevel surgery in cerebral palsy: results of a population-based health care programme and new techniques to reduce spasticity. J Pediatr Orthop B. 2005;14:269-273.
13. Hanna SE, Rosenbaum PL, Bartlett DJ, Palisano RJ, Walter SD, Avery L, Russell DJ. Stability and decline in gross motor function among children and youth with cerebral palsy aged 2 to 21 years. Dev Med Child Neurol. 2009;51:295-302.

14. Harvey A, Baker R, Morris ME, Hough J, Hughes M, Graham HK. Does parent report measure performance? A study of the construct validity of the Functional Mobility Scale. Dev Med Child Neurol. 2010;52:181-185.

15. Hicks JL, Schwartz MH, Arnold AS, Delp SL. Crouched postures reduce the capacity of muscles to extend the hip and knee during the single-limb stance phase of gait. J Biomech. 2008;41:960-967.

16. Holsbeeke L, Ketelaar M, Schoemaker MM, Gorter JW. Capacity, capability, and performance: different constructs or three of a kind? Arch Phys Med Rehabil. 2009;90:849-855.

17. Jahnsen R, Aamodt G, Rosenbaum P. Gross Motor Function Classification System used in adults with cerebral palsy: agreement of self-reported versus professional rating. Dev Med Child Neurol. 2006;48:734-738.

18. Jahnsen R, Villien L, Egeland T, Stanghelle JK, Holm I. Locomotion skills in adults with cerebral palsy. Clin Rehabil. 2004;18:309-316.

19. Johnston TE, Moore SE, Quinn LT, Smith BT. Energy cost of walking in children with cerebral palsy: relation to the Gross Motor Function Classification System. Dev Med Child Neurol. 2004;46:34-38.

20. Liao HF, Jeng SF, Lai JS, Cheng CK, Hu MH. The relation between standing balance and walking function in children with spastic diplegic cerebral palsy. Dev Med Child Neurol. 1997;39: $106-112$.

21. Mattsson E, Andersson C. Oxygen cost, walking speed, and perceived exertion in children with cerebral palsy when walking with anterior and posterior walkers. Dev Med Child Neurol. 1997;39:671-676.

22. Miller F. Cerebral Palsy. New York: Springer Publications; 2005.

23. Nordmark E, Hagglund G, Lagergren J. Cerebral palsy in southern Sweden. I. Prevalence and clinical features. Acta Paediatr. 2001;90:1271-1276.

24. Palisano R, Rosenbaum P, Walter S, Russell D, Wood E, Galuppi B. Development and reliability of a system to classify gross motor function in children with cerebral palsy. Dev Med Child Neurol. 1997;39:214-223.

25. Palisano RJ, Hanna SE, Rosenbaum PL, Tieman B. Probability of walking, wheeled mobility, and assisted mobility in children and adolescents with cerebral palsy. Dev Med Child Neurol. 2010; 52:66-71.

26. Palisano RJ, Kang LJ, Chiarello LA, Orlin M, Oeffinger D, Maggs J. Social and community participation of children and youth with cerebral palsy is associated with age and gross motor function classification. Phys Ther. 2009;89:1304-1314.

27. Palisano RJ, Rosenbaum P, Bartlett D, Livingston MH. Content validity of the expanded and revised Gross Motor Function Classification System. Dev Med Child Neurol. 2008;50:744-750.

28. Palisano RJ, Shimmell LJ, Stewart D, Lawless JJ, Rosenbaum PL, Russell DJ. Mobility experiences of adolescents with cerebral palsy. Phys Occup Ther Pediatr. 2009;29:135-155.

29. Palisano RJ, Tieman BL, Walter SD, Bartlett DJ, Rosenbaum PL, Russell D, Hanna SE. Effect of environmental setting on mobility methods of children with cerebral palsy. Dev Med Child Neurol. 2003;45:113-120.

30. Prevalence and characteristics of children with cerebral palsy in Europe. Dev Med Child Neurol. 2002;44:633-640.

31. Raja K, Joseph B, Benjamin S, Minocha V, Rana B. Physiological cost index in cerebral palsy: its role in evaluating the efficiency of ambulation. J Pediatr Orthop. 2007;27:130-136.

32. Rose J, Medeiros JM, Parker R. Energy cost index as an estimate of energy expenditure of cerebral-palsied children 
during assisted ambulation. Dev Med Child Neurol. 1985;27: 485-490.

33. Rosenbaum PL, Walter SD, Hanna SE, Palisano RJ, Russell DJ, Raina P, Wood E, Bartlett DJ, Galuppi BE. Prognosis for gross motor function in cerebral palsy: creation of motor development curves. JAMA. 2002;288:1357-1363.

34. Rumeau-Rouquette C, du Mazaubrun C, Mlika A, Dequae L. Motor disability in children in three birth cohorts. Int J Epidemiol. 1992;21:359-366.

35. Strauss D, Ojdana K, Shavelle R, Rosenbloom L. Decline in function and life expectancy of older persons with cerebral palsy. Neurorehabilitation. 2004;19:69-78.

36. Surveillance of cerebral palsy in Europe: a collaboration of cerebral palsy surveys and registers. Surveillance of Cerebral Palsy in Europe (SCPE). Dev Med Child Neurol. 2000;42:816-824.

37. Tefft D, Guerette P, Furumasu J. Cognitive predictors of young children's readiness for powered mobility. Dev Med Child Neurol. 1999;41:665-670.
38. Waters RL, Mulroy S. The energy expenditure of normal and pathologic gait. Gait Posture. 1999;9:207-231.

39. Westbom L, Hagglund G, Nordmark E. Cerebral palsy in a total population of 4-11 year olds in southern Sweden. Prevalence and distribution according to different $\mathrm{CP}$ classification systems. BMC Pediatr. 2007;7:41.

40. Woollacott MH, Burtner P, Jensen J, Jasiewicz J, Roncesvalles N, Sveistrup H. Development of postural responses during standing in healthy children and children with spastic diplegia. Neurosci Biobehav Rev. 1998;22:583-589.

41. Wren TA, Rethlefsen S, Kay RM. Prevalence of specific gait abnormalities in children with cerebral palsy: influence of cerebral palsy subtype, age, and previous surgery. J Pediatr Orthop. 2005;25:79-83.

42. Young NL, Williams JI, Yoshida KK, Bombardier C, Wright JG. The context of measuring disability: does it matter whether capability or performance is measured? J Clin Epidemiol. 1996; 49:1097-1101. 